Ethiopian Journal of Environmental Studies \& Management 8(1): 57 - 68, 2015.

ISSN:1998-0507

doi: http://dx.doi.org/10.4314/ejesm.v8i1.6

Submitted: October 27, 2014

Accepted: January 14, 2015

\title{
UNDERSTANDING GREEN AND SUSTAINABLE CONSTRUCTION IN LAGOS, NIGERIA: PRINCIPLES, ATTRIBUTES AND FRAMEWORK
}

*NWOKORO, I. ${ }^{1}$ AND ONUKWUBE, H. ${ }^{2}$

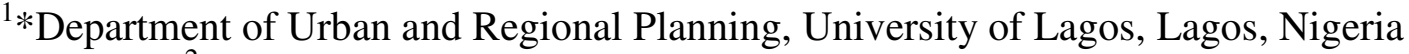

${ }^{2}$ Department of Building, University of Lagos, Lagos, Nigeria

\begin{abstract}
The research examined the concepts, principles and attributes in understanding sustainable and green construction as well as current practices and challenges in Lagos, Nigeria using both quantitative and qualitative methods of data collection. The sample frame is the total number of built industries registered and practising professionals in Lagos. A total number of 85 respondents were randomly selected for study from each group. A 5-point likert scale was used to assess respondents' judgement on the identified social, economic, bio-physical and technical indicators. Focus group discussions (FGDs) were also conducted with professional groups to corroborate the primary information. For a wider coverage, three different construction sites were selected to reflect income neighbourhoods-Lekki (high income), Yaba (medium income) and Bariga (low income). Data Collected were analysed using the mean item score. A multi- stage framework based on environmental assessment and management systems for construction projects was utilised. Research findings indicate that the most important factors considered for sustainable construction with their mean item scores are quality of working conditions (0.852), strengthening and enforcement of relevant laws and regulations (0.872), encouraging construction waste management (0.819), and design for flexibility and adaptability. Results from the FGDs indicate that the current practice on sustainable construction does not take into consideration integrated design process, acoustic and visual comfort in the planning and construction of sustainable projects. The research therefore, concludes that government should improve existing laws to enhance quality of working life, education, training as well as knowledge management for all stakeholders in sustainable construction.
\end{abstract}

Key Words: Sustainable construction, Green construction, Construction industry, Framework

\section{Introduction}

Sustainable construction has emerged as a guiding paradigm to create a new kind of built environment, while Ofori (2001) defines it as one that meets the needs of humans in the present without limiting the ability of future generalisations to meet their own needs. The creation, operation

*Corresponding Author: Nwokoro, I.

Email: Ifunanya66@yahoo.com and disposal of the built environment dominate humanity's impact on the natural world (Kibert et al., 2000). In addition, exposure to road traffic noise is the dominating source of community noise in the urban environment although it has been assessed either from subjective reports or without consideration of important factors 
that may influence the individual exposure level—for example, window type, bedroom window orientation and type of residence(Bluhm, et al., 2007). Similarly, in the study by Bornehag et al (2001), several epidemiological investigations concerning indoor environments have indicated that "dampness" in buildings is associated to health effects such as respiratory symptoms, asthma and allergy.

Sustainable development therefore, involves meeting the needs of the present without compromising the ability of future generations to meet their own needs (United Nations, 1987). A primary goal of sustainability is to reduce humanity's environmental or ecological footprint on the planet. Sustainable development has given rise to green buildings. Most green building practices fall into seven basic categories: energy saving, land saving, storm water runoff-reducing, material conservation and pollution reduction (ECO Northwest, 2001). A green building uses an average of $30 \%$ less energy than conventional building (Economist, 2004). Material waste generated during construction is reduced or recycled. Energy efficiency is improved, perhaps by relying on the use of natural light and ventilation or solar power. Less water is used, or rainwater harvesting system is installed to ensure wiser use. Measures taken to make buildings and construction more sustainable rely increasingly on life cycle approaches. Construction is a major and primary sector of the Nigerian economy and its consideration of the issues of sustainability covers a huge spectrum of the sector (Nwafor, 2006). Thus, the role buildings play is fundamental to the realisation of sustainable development. Public awareness of environmental issues has increased significantly in Nigeria. Property owners and clients are seeking commercial buildings that meet acceptable environmental and health levels. Unfortunately, there is lack of institutional structures promoting green buildings; awareness on the part of clients, tenants, professionals in the built environment and other stake holders; professional capacity to incorporate green building issues and opportunities and; financial resources to undertake green building construction and upgrades. The aim of this paper therefore is to examine the principles, attributes, current practices and challenges of sustainable construction in Lagos, Nigeria. This study addressed the following research questions-(a) what importance is attached to attributes of sustainable construction in Lagos? (b) What are the current practices and challenges facing sustainable construction in Lagos? (c) How can the proposed framework address the challenges of sustainable construction in the study area?

A Framework for the attainment of Sustainable Construction

The essence of this framework is to suggest how sustainable construction can be achieved. We are of the opinion that Environmental impact Assessment (EIA) should be carried out during the planning and design stages of projects, provided that the traditional EIA is expanded to include assessment of all four 'indicators' of sustainable construction. It should also be undertaken in accordance with the processoriented principles of sustainable construction, and enforcement by FEPA, NPE and LASEPA for each project, during construction, operation and, where appropriate, even decommissioning. The framework and its components are summarized in Figure 1 and discussed below. In this paper, a broad meaning is 
given to the term 'environment', to include the physical, biological, social and economic indicators that affect the individuals and groups within the developmental area. 'Environmental impact Assessment' could include assessment of all four 'indicators' of sustainable construction. There is need to set up a sustainability policy. Such a policy would set the desired level of environmental performance. Construction organizations could adopt a general environmental policy which could inform policies for specific projects. At the level of individual construction projects, environmental policy would emanate from company policy, if available; relevant legal requirements, and the EIA for the project, which would identify those principles of sustainable construction deemed relevant to the project through consultation with interested parties at an early stage in the EIA. The second key requirement is to provide an organizational structure and to determine the responsibilities, authority, lines of communication and the resources needed to implement the EMS. An EMS would need to determine the required interactions between the various contractors, consultants and clients involved in the project. Similarly, lines of communication should link the organizations involved, and should also provide a connection with a range of interested and affected parties external to the construction process. The third key requirement is to develop an environmental management programme (EMP) that stipulates environmental objectives and targets to be met and work instructions and controls to be applied in order to achieve compliance with the environmental policy. At project level, the EMP would contain operational procedures for controlling various activities, which would include: work instructions for determining the manner of conducting an activity; inspection procedures to ensure that mitigating measures are applied; procedures for dealing with accidents and emergencies; and, procedures for the measurement of performance indicators. In construction, where the primary goals of the contractor and the environmental management team may be different, the EMP may need to rely on penalties and bonuses to ensure compliance with standards. The fourth key requirement is to undertake periodic audits of the environmental performance of the construction team and the effectiveness of the Environmental Management System. 


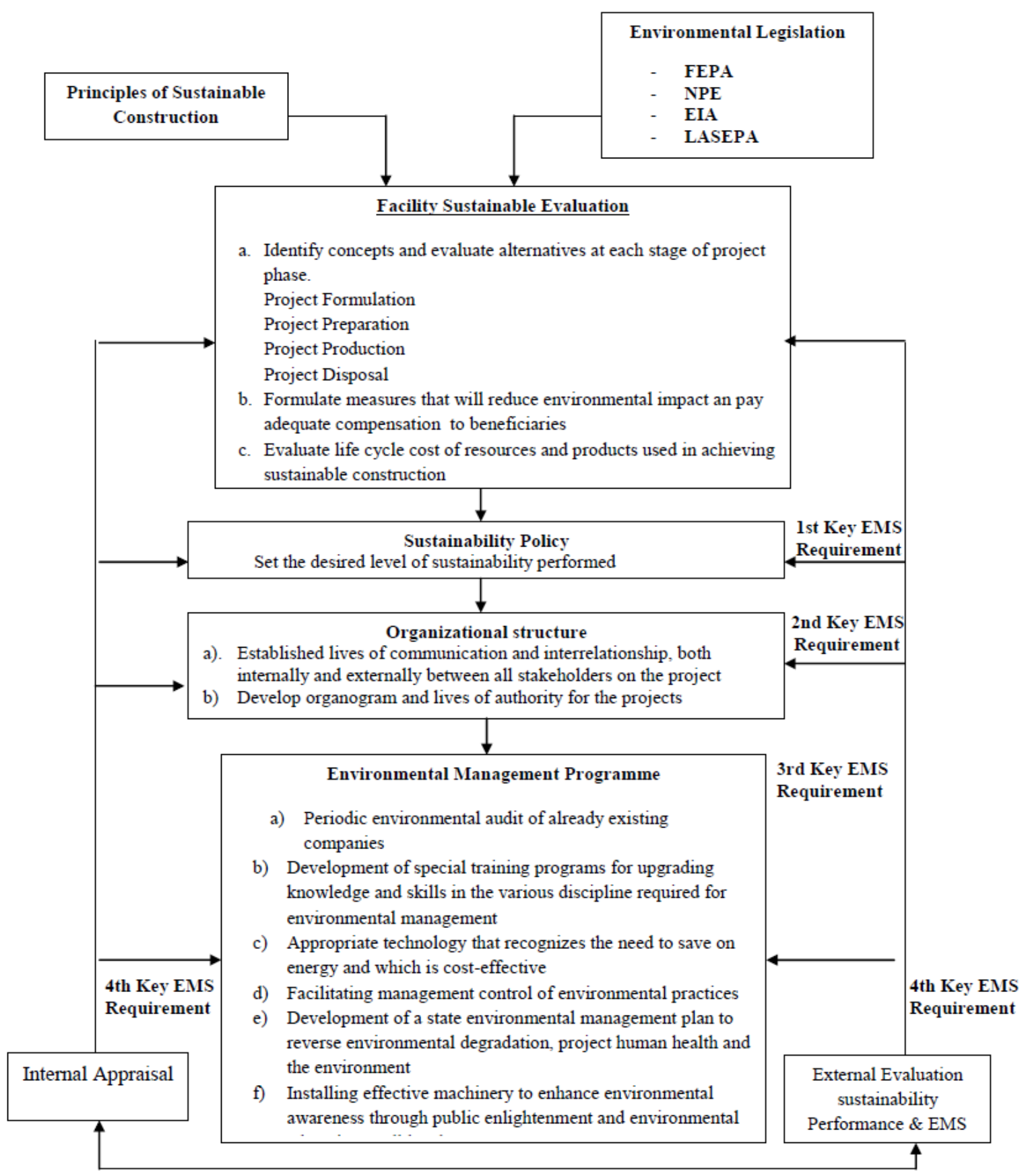

(Source: Adapted and modified from Hill and Bowen, (1997:234)

Figure 1: Framework for Sustainable Construction 


\section{Methodology \\ Study Area}

The study area comprises three neighbourhoods in Lagos metropolis shown in Figure 2. They are Lekki, Yaba and Bariga representing high, medium and low income residential neighbourhoods respectively. Lekki is a large naturally formed peninsula situated on the Atlantic Ocean side of Lagos Lagoon. Its geographical coordinates are $6^{0} 25^{\prime} 0$ " north, $4^{0} 6^{\prime} 0^{\prime \prime}$ east. The peninsula is approximately 70 to $80 \mathrm{~km}$ long, stretching from Victoria Island in the west to Refuge Island in the east, with an average width of $10 \mathrm{~km}$. Lekki is estimated to be about 60,000 hectares with the areas allocated for the Lekki Free Trade Zone and International airport excluded. Lekki's position represents a significant portion of undeveloped but accessible land in close proximity to Lagos for future growth and development with the Lekki area currently undergoing significant expansion and development due to the expansion and growth of Metropolitan Lagos.

Yaba is a predominantly medium income residential neighbourhood suburb in the mainland area of Lagos, known mostly to host an array of institutions of higher learning, like University of Lagos, Yaba College of Technology, Nigerian Institute of Medical research, Federal College of Education(Technical) as well as the popular Queens College. It is also a busy commercial hub with the popular Tejuosho market, the E-centre etc. It is easily accessible from Lagos Island, Ikeja, Surulere and Apapa areas of Lagos.

On the other hand, Bariga is one of the identified slum communities in Lagos Metropolis as well as one of the 17 independent settlements that make up Shomolu local government area. It is a low income residential community with all the characteristics of a slum area providing shelter for not only fishing communities but also for low income earners such as artisans traders and civil servants. Its proximity to Lagos Lagoon in the North and to Ilaje slum in the south has being of great influence in the influx of people seeking means of livelihood and cheaper accommodation. Drainage is poor in Bariga, particularly abutting the Lagos Lagoon and third mainland bridge. 


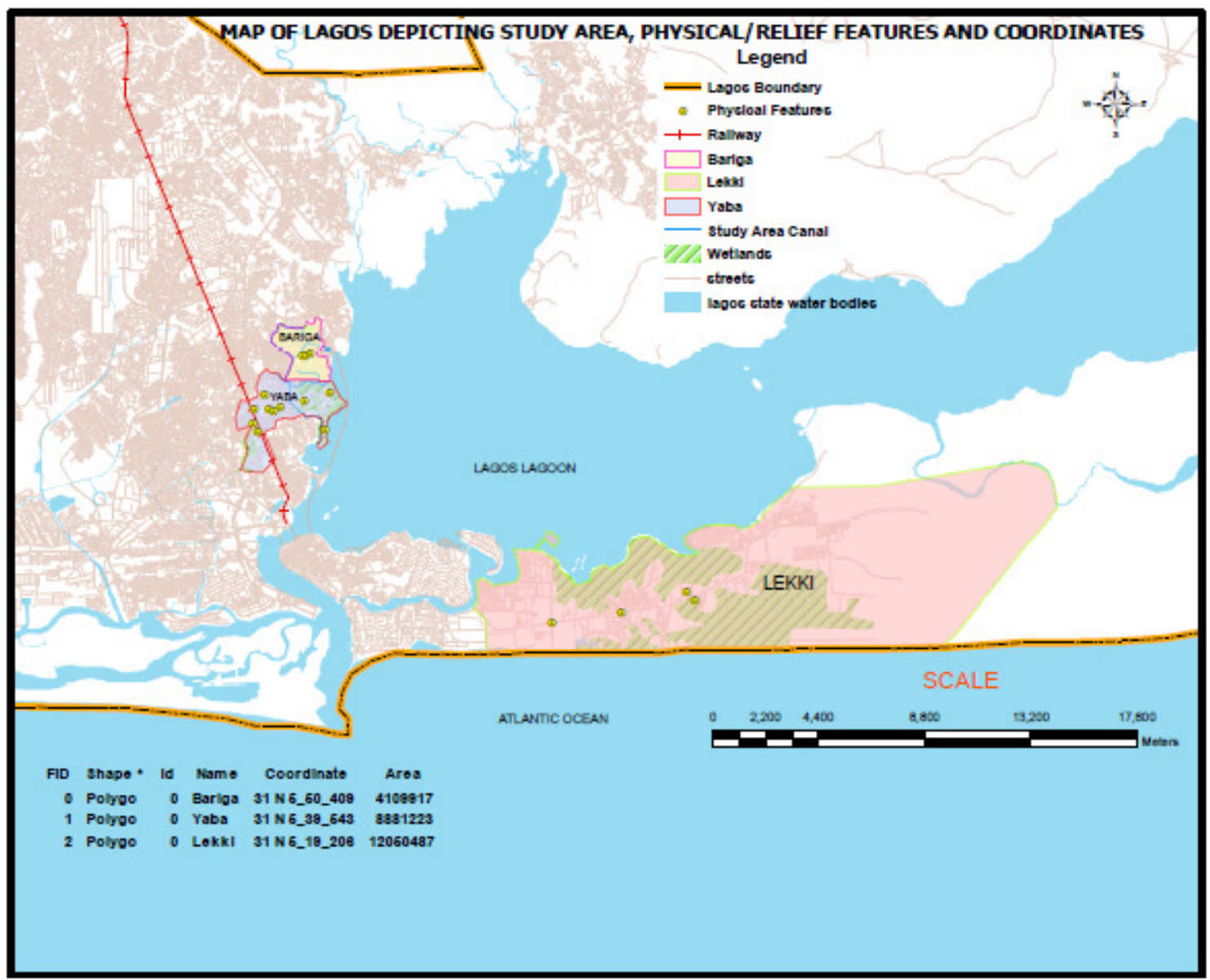

Figure 2: Map showing the study area

\section{Data Collection}

The study embraces both quantitative and qualitative methods of data collection. Relevant information is sourced from professionals in the construction industry, contractors, developers and clients. Using a structured questionnaire, information on how social, economic, bio- physical and technical indicators facilitate sustainable construction are elicited. Respondents were asked to indicate their judgement on identified social, economic, bio-physical and technical indicators. A 5-point scale was used to assess the importance of these factors. Section A addresses questions on name and type of organisation, years of construction industry experience. For each factor, an important index was determined. Questions on section B to F are quantitative in nature. Section $B$ comprises nine questions on social attribute of sustainable construction while section $\mathrm{C}$ comprises twelve questions on economic attribute of sustainable construction. Sections D, E and F comprise eight, six and six questions on bio physical, technical and process-oriented principles of sustainable construction respectively. The sample frame is the total number of registered professionals in the built industry in Lagos. A total number of 85 respondents were randomly selected for study from each group. In addition, two construction sites each were randomly selected and visited in 3 different income class neighbourhoods, thus, Lekki (high 
income), Yaba (medium income) and Bariga (low income).

Focus group discussions (FGDs) were also conducted with all the above groups to corroborate the primary information. This involved a meeting of ten (10) stakeholders drawn from professionals of the built industry in each of the three selected neighbourhoods. These groups were also gender and age sensitive to achieve diverse information. The work of Sultan (2005) was adapted for the quantitative aspect of the study because of the similarity of data in both researches. The response format designed by Sultan (2005) was altered. In this study instead of using a 3-point likert scale used by Sultan, a 5-point likert scale was used to achieve operationality of variables. Cronbach's alpha is a measure of internal reliability. This is bound by 0 and 1 , with measures closer to 1 representing strong reliability for the items in the research instrument. Data Collected are analysed with using mean item score. The sustainability instrument in this study recorded a Cronbach's alpha value of 0.91 and the data collected was analysed using statistical packages for social sciences (SPSS).

\section{Results and Discussion}

Data collected from Section A of the research instrument shows that $24(28 \%)$ of the respondents are consultants, 21(25\%) are developers, 20 (23.5\%) are contractors while the remaining 20 (23.5\%) are clients. Majority of the respondents 35 (41\%) had more than 25 years construction industry experience, while 28 (33\%) had experience ranging between (15-20) years. Others are $13(15 \%)$ for industry experience ranging between (10-14) years while the last group recorded $10(11 \%)$ for industry experience of (5-9) years. The implication of this result is that most of the respondents had enough knowledge and experience to make useful contribution to this area of research. The information elicited from the respondents were discussed along the lines of the different attributes of sustainability thus; social, economic, bio physical, technical and process oriented. This is further supported by the responses from the FGDs conducted in three different income residential areas. The ranking of these various indicators corresponds with the respondents need in order of importance.

Table 1: Relative Index of Social Indicators in "Sustainable" Construction

\begin{tabular}{lcc}
\hline Social Indicators & Mean Item Score & Ranking \\
\hline Quality of working conditions & 0.852 & 1 \\
Education and training & 0.845 & 2 \\
Knowledge management & 0.833 & 3 \\
Impact on employment & 0.795 & 4 \\
Health and safety & 0.762 & 5 \\
Innovative potential & 0.760 & 6 \\
Social characteristics and cultural & 0.718 & 7 \\
diversity in development planning & & \\
Societal product benefit & 0.694 & 8 \\
Societal dialogue & 0.663 & 9 \\
\hline
\end{tabular}


Table 1 reveals that most respondents rated quality of working conditions very high (Mean item score $=0.852$ ) as an important social factor in achieving green construction. This means that the respondents expect improved working conditions, fringe benefits and social amenities that will facilitate better standard of living. This finding supports the contribution of Hill and Bowen (1997) in their study on principles of sustainable construction. The finding of Sultan (2005) in this area of study is also in agreement with this result. Education and training, and knowledge management are ranked $2^{\text {nd }}$ and $3^{\text {rd }}$ respectively. This is a major factor in the developed countries where sustainable construction has been achieved. Respondents agreed that implementing skills training and capacity enhancement will help the disadvantaged workers. This will also create awareness about the benefits of green construction. Other social factors that were ranked high by respondents are impact on employment, health and safety and innovative potential. Currently the rate of employment is high and this contradicts the purpose of social sustainability. These factors are important factors that must be taken into consideration in planning for social sustainability.

Table 2: Relative Index of Economic Indicators in "Sustainable" Construction

\begin{tabular}{lll}
\hline Economic Indicators & $\begin{array}{l}\text { Mean Item } \\
\text { Score }\end{array}$ & Ranking \\
\hline Strengthening the law and regulations in construction & 0.872 & 1 \\
Strategies for sustaining the continuity of affordable & 0.833 & 2 \\
infrastructure projects. & & \\
Sustained and efficient use of resources and materials & 0.828 & 3 \\
Choose environmentally responsible suppliers and contractors & 0.826 & 4 \\
Local material protection policy & 0.816 & 5 \\
Energy - Efficiency policies in Design and Construction & 0.798 & 6 \\
Pricing policies & 0.793 & 7 \\
Improve administration effectiveness and reduce bureaucratic & 0.788 & 8 \\
procedures & & \\
Ensure financial affordability for intended beneficiaries & 0.767 & 9 \\
Sustained employment opportunities & 0.760 & 10 \\
Credit and Policies to select projects & 0.760 & 11 \\
Labour - intensive construction policies & 0.734 & 12 \\
\hline
\end{tabular}

For the economic indicators for sustainable construction, strengthening the law and regulations in construction ranked highest with a mean item score of 0.872 as shown in table 2. This includes sorting out all legal rights for investors and tenures via legal agencies to ensure the well conduct of the industry activities in a sustainable and efficient manner. The respondents also feel strongly about getting strategies for sustaining the continuity of affordable infrastructure projects and sustained and efficient use of resources and materials as these indicators ranked $2^{\text {nd }}$ and $3^{\text {rd }}$ respectively. The choice of suppliers and contractors who are environmentally responsible in addition to enforcing local material protection policy were other economic factors considered important for sustainable construction. Based on the mean item score of these factors all fall under the classification of very important and important economic indicators, this findings agrees with literature (Sultan, 2005). 
Table 3: Relative Index of Bio physical Indicators in "Sustainable" Construction

\begin{tabular}{lll}
\hline Bio Physical Indicators & $\begin{array}{l}\text { Mean Item } \\
\text { Score }\end{array}$ & Ranking \\
& 0.819 & 1 \\
Encourage construction waste management & 0.816 & 2 \\
Renewable building materials & 0.814 & 3 \\
Project design facilities & 0.805 & 4 \\
Promote the use of rapidly - renewable materials & 0.795 & 5 \\
Prevention of pollution from construction activity & 0.791 & 6 \\
$\begin{array}{l}\text { Designs that takes into consideration existing cultural } \\
\text { patterns and behaviours }\end{array}$ & 0.741 & 7 \\
Reduction of energy use & 0.704 & 8 \\
$\begin{array}{l}\text { Water use reduction and conservation and rainwater } \\
\text { collection. }\end{array}$ & \\
\hline
\end{tabular}

The ranking of certain bio physical factors that enhance sustainability in construction is highlighted in table 3 . Respondents strongly agree that waste management in construction should be encouraged. This indicator is ranked first (mean item score $=0.819$ ). This is a major challenge in most Nigerian construction sites and also corroborated by the FGDs across income areas. The inability to manage construction waste leads to air pollution and other health hazards. This construction waste problem manifested seriously at all construction sites visited. Another very important bio physical indicator for sustainable construction is the use of renewable building materials from sustainable sources. This will reduce the cost of maintenance due to the durability of materials used. The issue of renewability is considered as a key factor by the respondents as promotion of the use of rapidly - renewable materials also rank high. Table 3 shows other details of relative index of bio physical indicators in sustainable construction. All the indicators based on their respective (MIS) are very important factors, hence their consideration in sustainable construction is very essential. This agrees with the observation of (Wolley, 2000) that these factors will facilitate the attainment of sustainable construction.

Table 4: Relative Index of Technical Indicators in "Sustainable" Construction

\begin{tabular}{lcc}
\hline Technical Indicators & Mean Item Score & Ranking \\
Design for flexibility and adaptability & 0.875 & 1 \\
Design for durability of exposed building parts & 0.828 & 2 \\
Pursue quality in creating the built environment & 0.814 & 3 \\
Use serviceability to promote sustainable construction & 0.784 & 4 \\
Construct durability of exposed building parts & 0.778 & 5 \\
Revitalize existing urban infrastructure. & 0.764 & 6 \\
\hline
\end{tabular}

Both results from questionnaire information and FGDs revealed that the most important technical indicator for sustainable construction is Design for flexibility and adaptability (item mean score $=0.875)$ as shown in table 4 . Design for durability of exposed building parts and ensuring quality in creating the built environment are other two highly ranked indicators. Table 4 further indicates that the 
other factors were not considered necessary for green construction. To achieve this in Nigeria, the technological base has to be enhanced. Participants at the FGDs also showed concern at the low level of infrastructural and technological base which affect the quality of building materials and design.

Focus Group Discussions on Current Practices and Challenges of Sustainable Construction

Participants at the FGDs are of the opinion that the current practice on sustainable construction does not take into consideration integrated design process, acoustic and visual comfort in the planning and construction of sustainable projects. However, some participants are of the opinion that they apply the principles of site suitability, spatial comfort and building integrity in the sustainable projects that they were involved.

\section{Conclusions}

This research demonstrates how sustainability can be viewed in the context of Nigeria. It points to the importance of process in any efforts at sustainable construction. Sustainable construction requires a process that looks at sustainability comprehensively, exploring each of its component dimensions to discern its fit and relevance to a given context. This study also expands the current literature on sustainable construction by carrying out a comprehensive overview of social, economic, biophysical and technical indicators associated with sustainable construction as well as the current practice and challenges facing sustainable construction (Hill and Bowen, 1997; Wolley, 2000; Sultan, 2005). Most research in this area of study has been qualitative in nature. This study has gone a step further by adding quantitative dimension to identified social, economic, biophysical and technical indicators. This prioritizing will guide policy thrust in the area of sustainable construction. Another major contribution of this study is the modified multi- stage framework developed for stakeholders in sustainable construction. From a practical perspective, this study's results have implications for stakeholders in sustainable construction. First, our findings suggest that effective enforcement of existing laws on the environment will definitely encourage the practice of sustainable construction. Further the results shows that improvement on quality of working life, education and training of stakeholders will facilitate rapid growth in application of principles of sustainable construction. This agrees with the opinion of Hill and Bowen (1997).

$>$ The prioritization of social needs clearly shows that to achieve social sustainability in Nigeria, emphasis is on quality of working life, education and training as well as knowledge management.

$>$ The ranking of economic indicators of sustainable construction in Nigeria indicates that strengthening of existing laws, efficient use of resources, appointment of environmentally responsible contractors and local material protection are essential factors necessary for attainment of economic sustainability in construction.

$>$ The application of efficient waste management system, the use of renewable construction materials and effective use of project design facilities will facilitate the attainment of biophysical sustainability in Nigeria

$>$ Design for flexibility, durability, adaptability and quality are essential 
factors necessary for the attainment of technical sustainability in construction.

Compliance with relevant legislation and regulations, ability to carry out preliminary assessment of purposes and activities as well as utilize a life cycle framework and manage activities through the setting of targets are essential factors necessary for attainment of sustainable construction.

$>$ Emphasis should also be placed on integrated design process, site suitability, acoustic, visual, spatial and thermal comforts as well as building integrity in the practice of sustainable construction.

$>$ A multi- stage framework for sustainable construction is proposed which requires application of Environmental impact assessment (EIA) and implementation of Environmental Management Systems (EMS) for all stake holders involved in sustainable construction.

\section{Recommendations}

In the light of research findings and conclusions, the following recommendations are made in order to motivate the application of sustainable construction in Nigeria.

$>$ Government should improve existing laws in this area of research paradigm so as to improve quality of working life, education, training as well as knowledge management for all stakeholders in sustainable construction.

$>$ A clause should be introduced in the conditions of contract that will address environmental issues of sustainable construction as this will facilitate the appointment of environmentally responsible contractors and suppliers.
Seminars, workshops and lectures should be organised for all stakeholders in sustainable construction to address issues on efficient waste management, environmental management systems, and design for flexibility, durability, adaptability and the use of renewable construction materials.

\section{References}

Bluhm, G.L., Berglind, N., Nordling, E. and Rosenlund, M. (2007). Road Traffic Noise and Hypertension. Occupational Environmental Medicine, 64:122-126.

Bornehag, C.G., Blomquist, G., Gyntelberg, F., Ja“rvholm, B.,Malmberg, P., Nordvall, L., Nielsen, A., Pershagen, G. and Sundell, J. (2001). Dampness in Buildings and Health. Nordic Interdisciplinary Review of the Scientific Evidence on Associations between Exposure to 'Dampness in Building and Health Effects (NORDDAMP). Indoor Air, 11(2), 72-86.

Cole, R.J., Robinson, J., Brown, Z. and O'shea, M. (2008). Recontextualizing the notion of Comfort. Building Research \& Information, 36(4), 232-336.

ECONorthwest (2001). Green Building: Saving Money and the Environment; Opportunities for Louisiana. Eugene, Oregon:

Gardner, J.E. (1989). Decision Making For Sustainable Development: Selected Approaches to Environmental Assessment and Management. Environmental Impact Assessment Review, 9(4), 337- 66.

Griefahn, B. and Spreng, M. (2004). Disturbed Sleep Patterns and 
Limitation of Noise. Noise and Health, 6(22), 27-33.

Hill, R.C and Bowen, P.A (1997). Sustainable Construction, Principles and Framework for Attainment, Construction Management and Economics, 15, 223-239

Hillier, B. and Hanson, J. (1984). The Social Logic of Space. Cambridge: Cambridge University Press.

International Union for the Conservation of Nature and Natural Resources (IUCN) (1991). World Conservation Strategy. Gland, Switzerland.

Kibert, C., Sendzimir, J., and Guy, G. B. (Eds.) (2000). Defining an Ecology of Construction. Construction Ecology: Nature as the Basis for Green Buildings. New York: Spon Press, 728.

Lucas, G. and Rubel, W. (2004). The Moral Foundations of Leadership, Boston, MA: Pearson Education, 116.

Nwafor, J.C. (2006). Environmental Impact Assessment for Sustainable Development. Enugu: Eldermark Publishers.

Ochoa, C.E and Capeluto, I.G (2009). Advice Tool for Early Design Stages of Intelligent Facades based on Energy and Visual Comfort Approach. Energy Build, 480-488.

Ofori, G. (2000). Challenges of Construction Industries in Developing Countries: Lessons from various Countries. Proceedings of The $2^{\text {nd }}$ International Conference of the UB TG29 On Construction In Developing Countries Challenges facing The
Construction Industry in Developing Countries 15-17, November 2000, Gabarone, Botswana,1-3

Reed, G.R. and Gordon, E.B. (2000). Integrated Design and Building Processes. Building Research and Information, 28(5), 325-337.

Santoli, L. D. and Matteo, U.D. (2003). Building Energy and Environment Performance System, Building Systems, 24(2), 61-68.

Shove, E., Chappells, H., Lutzenhiser, L. and Hackett, B. (2008). Comfort in a lower Carbon Society. Building Research \&Information, 36(4), 307311.

Sultan, M.K (2005). The Construction Industry in Yemen: Towards Economic Sustainability. A Thesis Submitted in

Partial fulfilment of the requirement for Doctor of Philosophy.

United Nations, (1987). Report of the World Commission on Environment and Development. General Assembly Resolution 42/187.

Wallbaum, H, and Buerkin, C (2003). Concepts and Instruments for a Sustainable Construction Sector. Industry and Environment: Sustainable Building and Construction. United Nations Environment Programme, 26(2-3): 53-57.

Woolley, T. ( Ed). (2000). Green Building: Establishing Principles. Ethics and the Built Environment. Warwick Fox.Rutledge, London: 44-56. 